\title{
TEORIAS DA APRENDIZAGEM E DA EDUCAÇÃO COMO REFERENCIAIS EM PRÁTICAS DE ENSINO: AUSUBEL E LIPMAN
}

\author{
OLAVO L.S.F.* \\ MARCELLO FERREIRA ${ }^{\dagger}$ \\ Instituto de Física - IFD, Universidade de Brasília - UnB \\ Campus Darcy Ribeiro, Asa Norte, ICC-Centro CEP 70919-970 Brasília / DF
}

\begin{abstract}
Resumo
Os Mestrados Profissionais - especialmente aqueles na área de Ensino e, em particular, o Mestrado Nacional Profissional em Ensino de Física (MNPEF) - têm feito, em suas dissertações, amplo uso de referenciais teóricos que possam dar consistência aos produtos educacionais que são confeccionados como exigência para a conclusão do curso. Entretanto, de modo geral, esses referenciais teóricos raramente são considerados de maneira estrita nos próprios trabalhos, sendo, algumas vezes, até mesmo impossível divisá-los nas metodologias e nas sequências didáticas que lhes dão forma. Esse fenômeno pode estar associado ao fato de que muitos desses referenciais teóricos são calcados em Teorias de Aprendizagem, desenvolvidas no âmbito da Psicologia da Educação, estando, assim, estruturalmente muito amplos e distantes da prática de sala de aula, que são o foco dos produtos educacionais. Neste trabalho, revisamos essa questão, propondo que qualquer Teoria de Aprendizagem deve ser acompanhada de uma Teoria da Educação, de modo a fazer as necessárias conexões com a sala de aula. Como estudo de caso, é apresentada uma relação entre uma Teoria de Aprendizagem, desenvolvida por David Ausubel, e uma Teoria da Educação, desenvolvida por Mathew Lipman, mostrando suas interconexões e como uma articulação entre ambas pode gerar um referencial teórico muito mais robusto e concretizável.
\end{abstract}

Palavras-chave: Teorias de Aprendizagem. Teorias da Educação. Práticas de Ensino. Produtos Educacionais.

\footnotetext{
*E-mail: olavolsf@unb.br

†E-mail: marcellof@unb.br
} 


\begin{abstract}
Students attending the Masters Program Mestrado Nacional Profissional em Ensino de Física (National Professional Master Program in Physics Teaching) - MNPEF make wide use in their dissertations of a theoretical reference that can lend soundness to their educational products, made to comply to a demand of the Program. However, the theoretical reference adopted is rarely strictly assumed in the students dissertations. Indeed, the adopted theoretical reference is sometimes barely discernible in the methodologies and didactic sequences that give these dissertations structure and shape. This phenomenon may be related to the fact that many of these theoretical references are, in fact, Learning Theories developed in the context of the Psychology of Education. These Learning Theories, however, are structurally quite wide in scope and also distant from the usual practices of the classroom, which are the focus of educational products. In this work we revise this situation proposing that any Learning Theory should be connected to a Education Theory to make the necessary connection to the classroom activities. We also present, as a case study, an articulation between David Ausubel's theory of Meaningful Learning and Mathew Lipman's Theory of Education as a means to present a theoretical reference much more robust and concrete.
\end{abstract}

Keywords: Learning Theories. Theories of Education. Classroom Activities. Educational Products

\title{
1 Introdução: Teorias da Aprendizagem e Teorias da Educação
}

Em trabalhos desenvolvidos no âmbito dos Mestrados Profissionais em Física, é quase universal adotar-se a sequência de apresentação que se inicia com uma revisão bibliográfica do tema a ser abordado, continua apresentando o referencial teórico do trabalho para, em seguida, apresentar a metodologia a ser adotada. Os capítulos finais são reservados, geralmente, para uma análise dos resultados da aplicação da sequência didática desenvolvida e finalmente as conclusões.

Um trabalho científico desse porte deve apresentar um claro elemento de coesão formal expresso pelo requisito de que a metodologia faz a mediação entre as teorias expostas no referencial teórico e a sequência didática propriamente.

Não tem sido essa a impressão que advém das dissertações defendidas nesses Programas de PósGraduação. Não raro, a sequência didática é mesmo feita antes do desenvolvimento do referencial teórico e da metodologia, olvidando-se o pós-graduando de que a obediência à sequência das partes mencionadas é condição sine qua non para a obtenção da coesão formal a que nos referimos.

Assim, não raro, vê-se o pesquisador tentando "enfiar"(e esta expressão coloquial é proposital, para assinalar o caráter amador com que isso é, muitas vezes, realizado) seu produto no enquadramento produzido pelo referencial teórico, com as consequências que se podem divisar. De fato,

em muitos trabalhos publicados na área de ensino de física, constata-se que os "referenciais teóricos" - sobretudo aqueles formados por teorias psicológicas 
de aprendizagem - parecem não cumprir mais do que mero papel perfunctório, ou ainda, são invocadas apenas como um horizonte conceitual difuso e distante. (POLITO \& COELHO, 2018, p. 2-3).

O ponto central a se considerar aqui é que todo esse estado de coisas pode estar, de fato, indicando que, em muitos casos, os referenciais teóricos adotados se referem a Teorias Psicológicas de Aprendizagem e se mostram muito longe de seus contextos de aplicação concreta. Desse modo, mesmo que o pesquisador seguisse uma estrita sequência formal, tentando construir uma metodologia que ligasse o referencial teórico à sequência didática, aquele se encontra em um patamar tão abstrato que este falha em espelhá-lo.

O problema é que as Teorias de Aprendizagem, não raro, se desenvolvem em um contexto descritivo, apresentando os elementos que considera serem necessários para que a aprendizagem se dê - este é, claramente, o caso da teoria Ausubeliana. Assim,

enquanto as teorias psicológicas de aprendizagem são de natureza (predominantemente) descritiva; as teorias pedagógicas, as teorias de educação e as metodologias de ensino são de natureza (predominantemente) normativa. Como tais, essas últimas pretendem transcender o universo das primeiras na medida em que buscam ir além do mundo natural para alcançar as esferas moral, política, histórica e filosófica (POLITO \& COELHO, 2018, p. 3).

Entretanto, não seria lícito fazer uma clivagem estrita entre teorias de aprendizagem e teorias da educação. De fato, ocorre não raramente que determinadas teorias de aprendizagem subscrevem métodos ou técnicas propostas no âmbito de uma teoria de educação.

$\mathrm{O}$ fato é que, sem uma teoria da educação, que traga um caráter normativo para o referencial teórico, a teoria de aprendizagem eventualmente adotada mostra-se insuficiente, excessivamente abstrata para fornecer ao trabalho elementos metodológicos adequados para a concretude da sala de aula.

Nessa relação entre a dimensão descritiva das teorias de aprendizagem e a dimensão normativa das teorias da educação,uma inter-relação positiva deveria ser buscada no sentido de aperfeiçoar a ambas, até porque, sejam normativas ou descritivas, teorias jamais se estabelecem definitivamente para além de qualquer possibilidade de revisão.

Este é o objetivo precípuo deste trabalho em que se apresenta o caso concreto entre a teoria de aprendizagem de David Ausubel, descrita na segunda seção deste trabalho, e a teoria da educação (como a entendemos) de Mathew Lipman, descrita na terceira seção. Iremos mostrar, nas seções quatro e cinco, exatamente como se pode buscar a referida "inter-relação positiva"entre uma teoria da aprendizagem amplamente descritiva e uma teoria da educação eminentemente normativa. Na última seção, de número seis, tecemos nossas considerações finais.

\section{David Ausubel}

Para Ausubel, a aprendizagem de determinado conjunto de conceitos que formam um campo conceitual ou parte dele é a recepção deste conjunto de conceitos pela estrutura cognitiva do aprendiz, com os elementos que daí advém, como a necessidade de reorganização dessa estrutura, bem como da própria informação. 
Nesse sentido, o conceito fundamental da abordagem ausubeliana é aquele de estrutura cognitiva (que faz dele um adepto do Cognitivismo em Psicologia), entendida como uma estrutura hierarquicamente organizada de conceitos que se organizam como árvores relacionais. Outro conceito fundamental nessa abordagem é aquele de subsunçor, concebido como os conhecimentos pré-existentes na estrutura cognitiva do aprendiz. A aprendizagem, portanto, nos remete metaforicamente a um processo de ancoragem, via subsunçores, dos novos conhecimentos em uma estrutura cognitiva.

Nesse processo de ancoragem, tanto subsunçores como conhecimento novo sofrem mudanças importantes, uma vez que uma estrutura demanda modificações daquilo que se quer nela incorporar para que possa haver adequação, da mesma maneira que, do lado do objeto a ser aprendido, há também resistências hermenêuticas.

Ausubel propõe um esquema que apresenta como um processo ou princípio de assimilação em que a nova informação a encontra a estrutura cognitiva A do aprendiz. A assimilação consiste na construção do produto interacional A'a', durante certo período de tempo, em que A e a já se transformaram em A' e a' devido à chamada assimilação obliteradora que implica que os subsunçores de A também não voltam à sua forma original gerando o membro mais estável do produto A'a', isto é, o subsunçor modificado.

O grau de assimilação, em cada caso, depende da relevância do subsunçor, gerando os tipos de aprendizagem a seguir:

- aprendizagem subordinada: há uma relação de subordinação do novo material em relação à estrutura cognitiva preexistente, em que o conceito ou proposição potencialmente significativo a é assimilado sob a ideia mais inclusiva $\mathrm{A}$;

- aprendizagem superordenada: se dá por um conceito ou proposição significativo a, mais geral e inclusivo do que ideias ou conceitos já estabelecidos na estrutura cognitiva A;

- aprendizagem combinatória: quando não há relação de subordinação, nem de superordenação entre a e A. (MOREIRA, 2017a).

Segundo Ausubel, na aprendizagem significativa ocorrem, ainda, dois processos que se relacionam, a saber: a diferenciação progressiva e a reconciliação integrativa. Ao se submeter uma nova informação, esta é aprendida, e o conceito ou proposição inclusiva sofre modificações. A inclusão, que ocorre uma ou mais vezes, motiva a diferenciação progressiva da informação. A recombinação dos elementos existentes na estrutura cognitiva é denominada reconciliação integrativa (MOREIRA; MASINI, 2016).

Com essa visão do processo de aprendizagem, Ausubel é capaz de definir o que concebe como aprendizagem significativa justamente como o processo pelo qual uma nova informação estabelece uma relação com aspectos específicos e relevantes da estrutura já existente de conhecimento do indivíduo. Contrapondo-se a essa forma de aprendizagem, Ausubel define a aprendizagem mecânica como sendo aquela que, por não se reportar a subsunçores, apresenta caráter arbitrário e, portanto, pouco ou nada significativo. Assim, estabelecem-se dois polos opostos de um processo que, de fato, vive nas regiões intermediárias, entre uma aprendizagem totalmente significativa e uma aprendizagem absolutamente mecânica. 
Assim, verifica-se que houve aprendizagem significativa quando se observa a compreensão pura de um conjunto de conceitos, possibilitando a posse de significados claros, precisos, diferenciados e transferíveis (MOREIRA, 1999).

A questão que se põe, neste ponto, é em que medida seria possível amplificar o fenômeno da aprendizagem significativa. Dados os dois elementos a serem relacionados, subsunçores e novos conhecimentos, e o elemento mediador estrutural, que é a estrutura cognitiva, faz-se necessário construir uma ponte que permita adequar um ao outro, para, novamente de forma metafórica, criar uma ponte cognitiva entre ambos e potencializar a aprendizagem significativa. Assim, faz-se necessário a adoção de organizadores prévios, determinados a partir dos dois elementos da relação, como procedimentos de adequação cognitiva.

Evidentemente, o processo de ancoragem depende sempre da riqueza dos subsunçores envolvidos, sendo de se esperar que à medida que o aprendiz desenvolve tais elementos, mais fundamento para novas aprendizagens significativas aparecerão, tornando a estrutura cognitiva cada vez mais complexa.

Ausubel, por sua vez, divide a aprendizagem significativa em três tipos: representacional, de conceitos e proposicional (MOREIRA, 2017a).

- A aprendizagem representacional envolve a atribuição de significados a símbolos (as palavras, por exemplo);

- A aprendizagem de conceitos representa as regularidades em eventos ou objetos, sendo, de certo modo, representacional;

- A aprendizagem proposicional significa aprender ideias em forma de proposição.

É importante notar que Ausubel descreve processos psicológicos abstratos, sem fazer referência a metodologias específicas que possam ser adotadas no âmbito da sala de aula de modo a implementar a aprendizagem significativa.

Na Figura 1 apresentamos, sem intenção de sermos exaustivos, um mapa conceitual da teoria de aprendizagem de Ausubel. Fazemos isso para futura referência, quando mostrarmos as modificações trazidas pela adoção de uma teoria educacional como a de Lipman.

Um passo adiante, no sentido de propor uma Teoria da Educação com fundamento em uma Teoria Psicológica da Aprendizagem, é dado por Moreira quando sugere a elaboração de Unidades de Ensino Potencialmente Significativas (UEPS). Trata-se da proposta de se elaborar sequências didáticas com a seguinte estrutura:

- Levantamento dos conhecimentos prévios;

- Elaboração os organizadores prévios;

- Construção das situações-problema;

- Realização da diferenciação progressiva dos conceitos;

- Realização da reconciliação integradora;

- Efetivação do processo de consolidação; 


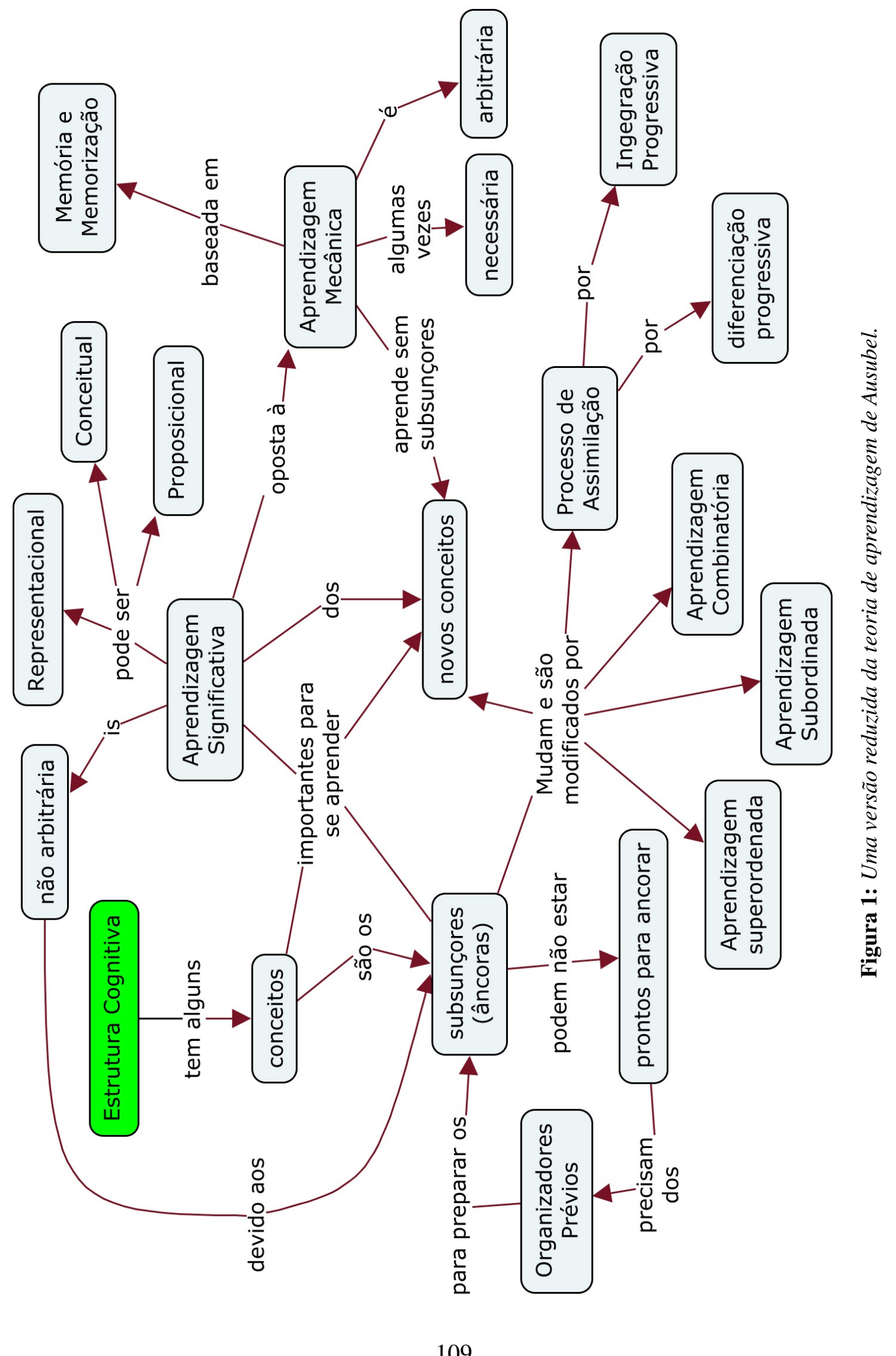


- A avaliação da aprendizagem significativa.

Sendo que, em todos esses elementos, há que se ressaltar o papel do professor, da interação social e da linguagem.

Aliado a isso, Moreira (2018, p. 3) propõe os seguintes passos para a elaboração de uma sequência didática de aprendizagem:

1. definir o tópico específico a ser abordado;

2. propor situações-problema, em nível bem introdutório, levando em conta o conhecimento prévio do aluno, que preparem o terreno para a introdução do conhecimento (declarativo ou procedimental) que se pretende ensinar;

3. criar/propor situação(ões) - discussão, questionário, mapa conceitual, mapa mental, situaçãoproblema, etc. - que leve (m) o aluno a externar seu conhecimento prévio, aceito ou não-aceito no contexto da matéria de ensino, supostamente relevante para a aprendizagem significativa do tópico (objetivo) em pauta;

4. uma vez trabalhadas as situações iniciais, apresentar o conhecimento a ser ensinado/aprendido, levando em conta a diferenciação progressiva.

5. retomar os aspectos mais gerais, estruturantes do conteúdo da unidade de ensino, porém em nível mais alto de complexidade em relação à primeira apresentação;

6. dar seguimento ao processo de diferenciação progressiva retomando as características mais relevantes do conteúdo em questão, porém de uma perspectiva integradora, ou seja, buscando a reconciliação integrativa;

7. a avaliação da aprendizagem através da UEPS deve ser feita ao longo de sua implementação, registrando tudo que possa ser considerado evidência de aprendizagem significativa do conteúdo trabalhado.

Entretanto, mesmo com todas essas recomendações ou regras, restam elementos relevantes ao processo de aprendizagem que não são contemplados, mesmo quando a aprendizagem pode ser considerada significativa. Um desses elementos define a dimensão crítica, autorreferente, em que o conhecimento voltase para si mesmo. Isso parece ocorrer justamente por Ausubel trabalhar com a ideia de um conhecimento externo na relação com um interno, e não aprofundar a questão da relação do conhecimento interno consigo mesmo.

Para uma mudança de foco, segundo Moreira (1999), faz-se necessário desenvolver uma aprendizagem significativa crítica, em que o aprendiz deixa de ser um receptor passivo e passa a articular significados que domina para obter os significados a serem aprendidos. Com isso, o individuo torna-se participativo na construção do conhecimento na medida em que faz a diferenciação progressiva e a reconciliação integradora e identifica as semelhanças e diferenças para reorganizar o novo conhecimento.

Para Moreira (2017b, p. 8), a "aprendizagem significativa crítica é aquela perspectiva que permite ao sujeito fazer parte de sua cultura e, ao mesmo tempo, estar fora dela" (grifo nosso). Na perspectiva 
antropológica, a aprendizagem significativa crítica dá ao individuo a possibilidade de participação ativa nas atividades desenvolvidas pelo grupo social e constrói uma visão que reconhece o momento em que a realidade se afasta ao ponto em que não se é mais captada pelo grupo.

Por meio da aprendizagem significativa crítica, Moreira acredita que o aluno poderá fazer parte da sua cultura sem ser subjugado por ela, conviver construtivamente com as mudanças de seu grupo social sem se deixar dominar, manipular informações sem o sentimento de impotência, a partir da ideia de que o conhecimento é uma construção social humana.

A fim de facilitar a implementação da aprendizagem significativa crítica em sala de aula, Moreira (2017b, p. 9) propõe nove princípios:

1. Princípio da interação social e do questionamento: questionamentos relevantes e substantivos trazem consigo elementos atrelados ao conhecimento prévio de maneira não arbitrária e não literal. Aprender a formular questões adequadamente é uma evidência de aprendizagem significativa crítica capaz de tornar o professor e o aluno epistemologicamente curiosos.

2. Princípio da não centralidade do livro de texto: o uso de materiais ou estratégias diversificados é também um princípio facilitador da aprendizagem significativa crítica.

3. Princípio do aprendiz como investigador: trabalha o aluno do ponto de vista da descoberta, em um processo que promova a adesão destes ao que se busca compreender (MOREIRA, 1999, p. 230).

4. Princípio do conhecimento como linguagem: a aprendizagem de uma nova linguagem é mediada pelo intercâmbio de significados, pela clarificação de significados e pela negociação de significados que é feita através dessa linguagem.

5. Princípio da consciência semântica: ao usar palavras para nomear as coisas, é preciso não deixar de perceber que os significados das palavras mudam (diacronia) e que a linguagem tem certo efeito fotográfico (sincrônico).

6. Princípio da aprendizagem pelo erro: utilizar o erro como ponto de partida para promover a aprendizagem significativa crítica através da autocorreção decorrente do erro devidamente identificado.

7. Princípio da desaprendizagem: tem o sentido de esquecimento seletivo. A aprendizagem significativa crítica vai se desenvolvendo na medida em que se é fruto do aprender a desaprender, quando se aprende a distinguir entre o relevante e o irrelevante no conhecimento prévio e na medida em que se aprende a libertar-se do irrelevante.

8. Princípio da incerteza do conhecimento: a aprendizagem significativa dos elementos de linguagem só será crítica quando o aprendiz perceber que as definições são invenções humanas, que tudo que se sabe tem origem em perguntas e que todo conhecimento é metafórico.

9. Princípio da diversidade de estratégias de ensino: este princípio sugere a diversidade de materiais educativos, assim como diversidade de estratégias instrucionais que possam promover o ensino centrado no aluno. Sugere o uso de outros recursos educativos como, por exemplo, as atividades 
Revista do Professor de Física • Brasília, vol. 2, n. 2 • 2018

colaborativas, seminários, projetos, pesquisas, entre outros, o que facilita a implementação dos demais princípios mediados pelo professor.

Desse modo, as noções de aprendizagem significativa crítica de Moreira estabelecem uma conexão entre as ideias de David Ausubel e Teoria de Educação de Mathew Lipman, que apresentamos a seguir.

\section{Mathew Lipman}

Em suas experiências como professor da Columbia University, Lipman percebeu em seus alunos uma grande dificuldade para construir raciocínios. Ao considerar o raciocínio um elemento funcamental (LIPMAN; OSCANYAN \& SHARP, 2001) para o desenvolvimento da ética, da codificação de experiências, da justificação de crenças, do desenvolvimento de processos de generalização, entre outros, Lipman foi levado a propor seu Programa de Filosofia para Crianças e Adolescentes.

Assim, o programa de Filosofia para Crianças e Adolescentes nasceu da busca por se estimular um pensamento articulado, estruturado, desenvolvendo estratégias concretas que promovam a atitude crítica, reflexiva, criativa e autônoma. Nesse sentido, o pensamento é um elemento central em sua Filosofia, que consideraremos aqui como uma Teoria da Educação.

Assim, Lipman define, inicialmente, o Pensar Crítico, que se relaciona mais imediatamente com nossa capacidade de julgar, ou seja, contribui com a solução de problemas, a tomada de decisões e a aprendizagem de novos conceitos (LIPMAN, 1995, parte II.). A capacidade de julgar, por sua vez, depende da habilidade em seguir critérios que permitem escolher e defender argumentos e ações. É, pois, uma ferramenta crucial para prever resultados de decisões e tem como característica fundamental a capacidade de ser autocorretivo e sensível ao contexto de uso.

Não se trata, portanto, de fazer com que os jovens simplesmente pensem, mas que possam ir além do simples pensar, tornando-se capazes de praticar um bom julgamento que caracteriza a interpretação profunda de um texto escrito, a redação equilibrada e coerente, a compreensão lúcida daquilo que ouvimos e o argumento persuasivo. (LIPMAN, 1995, parte II).

Lipman entende que o Pensar Crítico não é suficiente para se atingir a meta de um Pensar Superior, e considera também o Pensar Criativo, que assume como complementar àquele. Este último é o resultado de estímulos derivados das sensações (de caráter assimilativo) ou invenções (de caráter manipulativo). É uma forma de raciocínio ampliativo, uma vez se coloca para além do que já está estabelecido (LIPMAN, 1995, parte III).

Lipman define ainda o Pensar Cuidadoso como aquele que precede as ações a serem executadas, considerando aquilo que o indivíduo considera importante e valioso na construção do raciocínio.

A articulação desses três tipos de pensamento levam, segundo Lipman, ao Pensamento de Ordem Superior, que precisa ser conceitualmente rico, estruturado e investigativo. Neste sentido, o Pensamento de Ordem Superior tende a ser altamente significativo, entende Lipman. As características de riqueza e estruturação podem ser relacionadas com práticas características da abordagem fundamentada em Ausubel, como a da construção de mapas conceituais. O caráter investigativo, entretanto, aponta em um sentido que extrapola ao que se pode haurir da abordagem Ausubeliana. 
Assim, para que o Pensamento de Ordem Superior ocorra faz-se necessário desenvolver certas habilidades cognitivas de ordem superior. Tais habilidades são:

1. Habilidade de raciocínio: capacidade de haurir conclusões ou inferências a partir de conhecimentos prévios, de modo a garantir coerência e sistematicidade ao discurso;

2. Habilidade de formação de conceitos: capacidade de identificar vínculos conceituais e estabelecer relações entre conceitos, formando conceitos mais complexos;

3. Habilidade de investigação: capacidade de alcançar as soluções dos problemas postos pela realidade, estando fortemente relacionada com a capacidade de adotar o método científico;

4. Habilidade de tradução: capacidade de compreensão e reprodução, em sua própria linguagem, de discursos escritos ou falados.

Para concretizar tais habilidades Lipman propõe as chamadas Comunidades de Investigação (LIPMAN, 1995, parte IV), uma prática concreta em sala de aula. De fato, em seu uso cotidiano em sala de aula, as Comunidades de Investigação se estabelecem a partir de um diálogo no qual os conteúdos são inicialmente apresentados a partir das próprias suposições dos alunos (ou seja, em termos Ausubelianos, seus subsunçores, que agora passam a ser compatilhados por intermédio das Comunidades de Investigação).

Caberá ao processo dialógico, central para as Comunidades de Investigação, reposicionar as concepções dos alunos ao colocá-los em contato com perspectivas diferentes (e, eventualmente, contrárias) às suas, exigindo dos mesmos um esforço criativo e argumentativo para defender suas posições, ou flexibilidade para adotar posições diversas.

Nesse processo dialógico, o papel do professor é essencial, visto que cabe a ele estabelecer direcionamentos que estruturem tal processo de modo a se obter, ao final, uma ou mais concepções adequadas, segundo a perspectiva do Pensamento de Ordem Superior, para o fenômeno em discussão. Proceduralmente, o papel do professor é o de construir, na diacronia dialógica, os necessários organizadores prévios, em linguagem Ausubeliana. Importante ressaltar, entretanto, que esse elemento de intervenção deve ser realizado de dentro da Comunidade de Investigação, não de seu exterior, a partir da autoridade do professor.

Parece razoável imaginar que tal abordagem engendra uma adesão emocional e intelectual muito maior por parte dos alunos do que aquela que se obtém das já demonstradamente ineficientes aulas expositivas, uma vez que a adoção dessa pedagogia exige estratégias capazes de capacitar os envolvidos para situações de confrontação de ideias, questionamentos e inconformidade diante dos fatos, ampliando sua visão de mundo e de seu universo experiencial.

Para além do elemento procedural, relacionado à adoção das Comunidades de Investigação, e calcado na exigência de um alto poder de articulação conceitual decorrente dos embates nessas comunidades, Lipman propõe, em um contexto mais substantivo, a adoção da Filosofia como elemento transversal (ou central).

Na perspectiva que nos interessa aqui, a Filosofia (mas, principalmente, a História da Física), tem muito a contribuir com o acolhimento histórico de concepções prévias dos alunos, na medida em que mostra a eles que suas elocubrações já foram objeto de pensamento de eminentes filósofos naturais ou 
cientistas. Pode também contribuir imensamente no processo de organização e estruturação do diálogo nas Comunidades de Investigação, ao organizar tais concepções menos elaboradas a partir do desenvolvimento histórico concreto dos conceitos e ideias na Física, de conhecimento prévio restrito ao professor.

Essa defesa da História da Física (na perspectiva deste trabalho) como elemento transversal no ensino de conceitos físicos leva-nos diretamente à questão da interdisciplinaridade e de sua concretização no ambiente da sala de aula.

Na Figura 2, apresentamos um mapa conceitual em que estão indicadas as extensões que uma teoria educacional como a de Lipman realiza sobre uma teoria da aprendizagem, como a de Ausubel.

\section{Interdisciplinaridade}

Nesta seção, como exercício epistemológico de interdisciplinaridade, nos deslocaremos entre o pensamento social de Weber, a filosofia da liberdade de Michel Foucault e as apreensões epistemológicas de Sommerman, para buscar a construção de uma reflexão sobre a articulação entre teorias psicológicas e teorias educacionais, no âmbito das produções educacionais de programas de pós-graduação profissionalizantes na área de ensino

\subsection{Ascensão valorativa pela ótica de Weber: a (suposta) interdisciplinaridade como racionalização da ação}

A produção científica sobre a interdisciplinaridade tem crescido mundialmente, e particularmente no Brasil ${ }^{1}$, como se pode observar por buscas nos principais periódicos científicos e repositórios de dissertações e teses, sobretudo, nas áreas de educação e ensino.

A maior parte desses trabalhos, conforme endossam Mozena e Ostermann (2014), privilegiam discussões sobre (supostas) práticas escolares da interdisciplinaridade, em detrimento a fundamentos epistemológicos ou concepções.

Sem supervalorizar ou privilegiar uma ou outra ênfase sobre interdisciplinaridade nos campos da pesquisa e do ensino, a análise dessa tendência remete-nos ao fenômeno estrutural da racionalidade técnica (WEBER, 1994), pois fica evidente o afastamento entre um suposto polo produtor de conhecimento sofisticado, próprio das ciências e da universidade (como é o caso da epistemologia interdisciplinar) e outro polo, menos glamouroso e mais útil, pragmático (como é o caso do pesquisador ou profissional de educação que propõe ações supostamente interdisciplinares).

Para além da perspectiva de racionalização técnica - que, para Weber, corresponde a um processo dinâmico de compreensão histórico-social da técnica -, no plano social, a racionalização da ação tem por componente essencial

\footnotetext{
${ }^{1}$ Esse fenômeno é, em parte, justificado pelo declínio de perspectivas curriculares tradicionais, que sobrepujavam as ideias de "competências" e "habilidades", por outras de naturezas pseudocríticas, especialmente presentes nas novas Diretrizes Curriculares Nacionais Gerais da Educação Básica (DCNGEB) e nas novas Diretrizes Curriculares Nacionais do Ensino Médio (DCNEM), promulgadas pelo Conselho Nacional de Educação (CNE), respectivamente, nos anos de 2010 e 2012.
} 


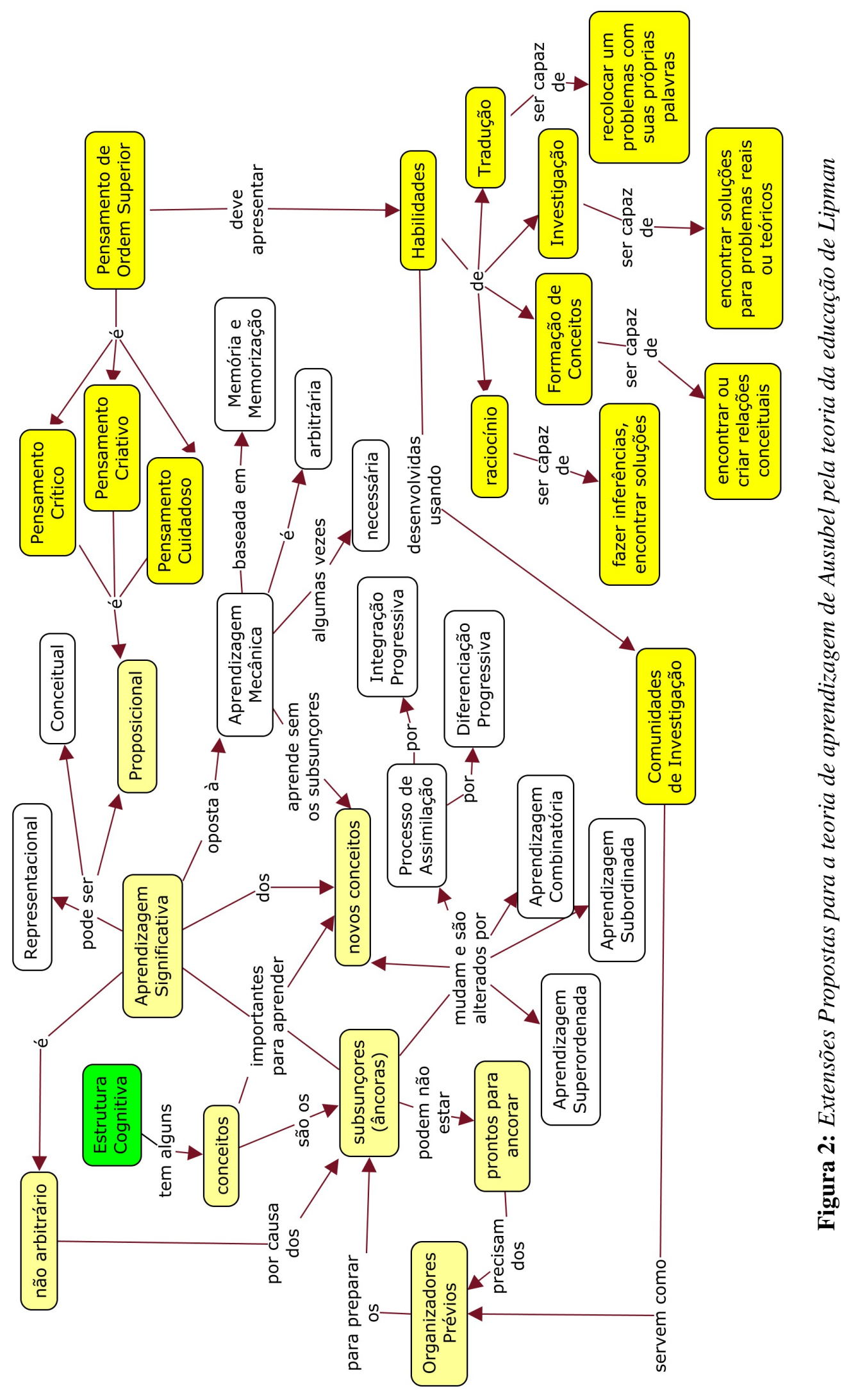




\section{[...] a substituição da submissão interna ao costume habitual pela adaptação}

planejada a determinadas situações de interesses. Esse processo, no entanto, não esgota o conceito de "racionalização"da ação. Pois pode suceder que essa ocorra, de maneira positiva, em direção a uma racionalização consciente de valores, porém, de maneira negativa, às custas não apenas do costume mas igualmente da ação afetiva e, finalmente, também em direção à ação puramente racional referente a fins e não crente em valores, às custas da ação racional em relação a valores (WEBER, 1994, p. 19, grifos nossos).

Nos planos individual, cultural e social, a crítica weberiana, portanto, assinala o crescente predomínio da racionalidade técnica. No contexto da formação e da prática docente, ela se manifesta em aspectos como: definição de objetivos, seleção de conhecimentos e metodologias, ações organizacionais, currículo, avaliação e, por fim, as qualidades formal e política dos processos de ensino aprendizagem. Trata-se, pois, da assunção de um paradigma da prática docente "como um modus operandi para a execução e reprodução (técnica) de conhecimentos produzidos por especialistas" (FERREIRA; LOGUERCIO, 2016, p. 401).

A racionalidade técnica torna-se, assim, um meio de apreciação valorativa das origens, dos meios e das possibilidades de ocorrência de determinado fenômeno; em amplo sentido, uma forma de se dizer por que e como determinados aspectos tomam forma em um contexto individual, cultural ou social.

Dessa perspectiva da racionalidade técnica, quer-se sublinhar e interrogar a ascensão do interesse pela interdisciplinaridade como objeto de pesquisa e ação de ensino; mais do que isso, problematizar a migração desse tipo de abordagem da posição de princípio pedagógico para o status de base de organização pedagógica, como se vê nos documentos oficiais (BRASIL, 1998; 2013).

\subsection{Antes da interdisciplinaridade, a disciplina}

Uma discussão devidamente epistemológica da interdisciplinaridade requer um aparte sobre o campo disciplinar. Para Foucault (2008), as disciplinas instituem regimes de verdade, cuja função é legitimar as relações de saber/poder nos respectivos espaços sociais. Trata-se, em termos mais singelos, de estabelecer o dizível e hierarquizar saberes e práticas numa dada ordem do discurso.

[...] chamamos "disciplinas"a conjuntos de enunciados que tomam emprestado de modelos científicos sua organização, que tendem à coerência e à demonstratividade, que são recebidos, institucionalizados, transmitidos e às vezes ensinados como ciências [...] (FOUCAULT, 2008, p. 200)

As disciplinas, por essa ótica, representando a ciência lato sensu, se ocupam da produção de verdades e da estabilização de conceitos e formas de operação do saber. A verdade, como saber, corresponde a um domínio sistemático de procedimentos voltados à instauração, veiculação e orquestração de afirmações, num dado regime de produção (FOUCAULT, 2008).

Desta feita, ainda segundo Foucault (2008), a sobrevivência das disciplinas pressupõe a institucionalização de meios estáveis para instituir verdades: campos lógicos, técnicas e operações. As disciplinas são, assim, conjuntos formais, estabilizados e procedimentados, voltados a gerar representações sobre os saberes, colocando-os em interação com o regime que os produz e engendra, além de imiscuí-los às relações de poder. 
Em última análise, as disciplinas correspondem à ordem do discurso, à forma como se idealiza, gera, mobiliza e articula saber/poder; à forma institucionalizada de regular condutas humanas e relações sociais, isto é, ao serviço de produzir corpos dóceis e úteis (FOUCAULT, 1987).

\subsection{Interdisciplinaridade: das contingências epistemológicas à proposição de ob- jeto, método e finalidade}

O próprio Foucault (1984, p. 13), em História da Sexualidade II - O Uso dos Prazeres, ressalta que: "existem momentos na vida onde a questão de saber se se pode pensar diferentemente do que se pensa, e perceber diferentemente do que se vê, é indispensável para continuar a olhar e a refletir". Partilhamos dessa perspectiva ao afirmar que o campo da interdisciplinaridade, em sua dimensão de abordagem didática, requer uma nova forma de comunhão teórica entre as disciplinas e os especialistas.

Referimo-nos, em particular, à perplexidade com que nos temos deparado com algumas concepções e propostas (pseudo)interdisciplinares, tanto no campo da produção científica e da prática escolar, quanto, especialmente, nos denominados "produtos educacionais", que correspondem a propostas de intervenção didática/aplicação educacional decorrentes de pesquisas em programas de pós-graduação profissionalizantes, especialmente nas áreas de ensino.

Tratam-se de concepções que vão desde uma inobservância epistemológica, passando por um viés meramente utilitarista, até a absurdas contravenções teóricas. É isso que denominamos de "contingências epistemológicas".

A esse propósito, recuperamos aqui a discussão de Sommerman (2015) sobre o objeto, o método e a finalidade da interdisciplinaridade. Articulando contribuições da evolução epistemológica do termo, encontradas em Piaget (1973), Jantsch (1973), Japiassú (1976; 2006), Klein (1990), Kockelmans (1997), Lattuca (2001), Fazenda (2003), Lenoir (2005), Repko (2008), o autor propõe a seguinte definição:

Interdisciplinaridade: interação prolongada e coordenada entre disciplinas acadêmicas, para a resolução de determinado problema complexo que pode ser resolvido por abordagens monodisciplinares, levando a:

- Integração dos diferentes discursos.

- Criação de uma terminologia comum ou um quadro conceitual comum (formando pontes entre as disciplinas).

- Formulação de uma metodologia comum, transcendendo ou na interface das epistemologias de diferentes disciplinas.

- Geração de um conhecimento novo (SOMMERMAN, 2015, p. 208).

Como objeto da interdisciplinaridade, Sommerman (2015, p. 209) propõe "os saberes das disciplinas das quatro grandes áreas do conhecimento acadêmico - ciências da natureza, ciências formais, ciências sociais e humanidade".

Como método (processos/etapas) da proposta interdisciplinar, Sommerman (2015) propõe as etapas propostas por Klein (1990, p. 188-189):

1a. definir o problema [questão, tópico, tema];

b. determinar os conhecimentos necessários, inclusive os representantes e consultores disciplinares apropriados, bem como modelos, tradições e literaturas 
relevantes;

c. desenvolver um quadro integrativo e questões apropriadas a serem investigadas;

2a. especificar determinados estudos a serem realizados;

b. engajar a "negociação dos papéis" (no trabalho em equipe);

c. coletar todo o conhecimento disponível e buscar informações novas;

d. resolver os conflitos disciplinares trabalhando para a construção de um vocabulário comum (e buscar uma aprendizagem recíproca no trabalho em equipe);

e. edificar e manter a comunicação mediante técnicas integrativas;

3a. cotejar todas as contribuições e avaliar sua adequação, relevância e adaptabilidade;

b. integrar as peças individuais para determinar um padrão para o relacionamento e a relevância mútuas;

c. confirmar ou não confirmar a solução [resposta] proposta; e

d. decidir sobre a gestão ou disposição da tarefa/projeto/cliente/currículo futuro.

e por Repko (2008, p. 247):

1) Identificar os conflitos entre os saberes das disciplinas envolvidas e localizar o motivo desses conflitos; 2) Criar um fundamento comum entre esses saberes ou insights; 3) Utilizar este fundamento comum para integrar os saberes ou insights conflitivos; 4) Produzir uma compreensão interdisciplinar do problema e testá-la.

Como finalidade da interdisciplinaridade, Sommerman (2015, p. 2010) indica:

distinguir e articular os saberes das diversas disciplinas acadêmicas para o tratamento de determinados problemas complexos que não podem ser resolvidos por abordagens monodisciplinares, multidisciplinares, nem pluridisciplinares; contribuir para uma formação mais global (Bildung) da pessoa e desenvolver a humanidade nos seres humanos, estruturando uma personalidade segundo certa paideia, ou seja, segundo um certo ideal civilizatório; incluir na pesquisa e no ensino as diferentes dimensões do sujeito pesquisador, professor, aluno; encontrar soluções cientificamente realizáveis e humanisticamente respeitáveis.

Apropriamo-nos, pois, dessas ideias de Sommerman (2015) sobre objeto, método de finalidade da interdisciplinaridade, para, de igual modo, concebê-la como uma mútua transferência de métodos, uma transversalização de conhecimentos entre as disciplinas (portanto, ainda inscrita na perspectiva disciplinar).

Entendemo-la como uma abordagem teórico-metodológica em torno de uma problemática não solúvel pelo acionamento ou mesmo pela justaposição disciplinar; além disso, que enfatiza a integração e o planejamento sistemático das áreas do conhecimento (disciplinas), na perspectiva da colaboração e da constituição de comunidades de investigação.

No enfrentamento de uma questão (ou de um problema), portanto, a perspectiva interdisciplinar atua articulando as disciplinas, que nesse percurso integram suas epistemologias e metodologias e seus saberes para a produção de novos conhecimentos comungados, sem que as disciplinas, per se, sejam alteradas após esse processo. 
O que seria, então, a proposição de uma aplicação (produto/proposição) educacional no ensino, senão a tentativa de delinear e solucionar um problema (no caso, uma melhoria ou uma inovação em práticas educacionais)?

Nesse ponto voltamos à perspectiva de Lipman, que estabelece de início uma dimensão interdisciplinar, na medida que apresenta o elemento histórico/filosófico como sendo aglutinador dos discursos intracientíficos ou disciplinares. Mais ainda, enxergamos na concepção das comunidades de investigação, como dissemos, a estratégia capaz de concretizar de maneira natural algumas das características apontadas anteriormente, uma vez que no processo de costrução comunitária e dialógica da solução ficam integrados, de maneira não artificial, os discursos intracientíficos e disciplinares àqueles propriamente filosóficos ou históricos. Tal integração engendra, por sua vez, a criação de um quadro conceitual comum.

Do ponto de vista do professor ou professores, caberia então projetar uma prática verdadeiramente interdisciplinar a partir, principalmente, de mapas conceituais em que estivessem negociadas as interconexões de conceitos advindos de elementos da Física e de conceitos propriamente filosóficos ou históricos associados ao tema da questão ou tópico previamente determinado. Neste caso específico, é a característica horizontal do mapa conceitual que estabelece o caráter integrativo responsável pelo resultado interdisciplinar genuíno.

Mais que isso, esse processo de construção de um panorama conceitual mais amplo em que a questão pode ser enquadrada permite um alargamento do conjunto de subsunçores que podem ser movimentados com a questão, engendrando uma situação em que os diferentes integrantes da comunidade de investigação, com seus diferentes conjuntos de subsunçores, poderão ser acessados pelo quadro conceitual mais geral previamente projetado com igual força, ainda que nele adentrem por diferentes portas conceituais.

Fica clara, portanto, a utilidade da programação conceitual das discussões, por parte dos professores, como estratégia para a facilitação de um ambiente discursivo (as comunidades) capaz de engendrar uma auto organização conceitual própria (a partir das várias contribuições/perspectivas individuais) que transborda daquela programada e se constitui como solução própria da comunidade.

O caráter auto referente dessa auto organização discursiva estabelece, na diacronia da construção dialógica da solução, um funcionamento sincrônico como organizadora prévia sucessiva e paulatina dos conjuntos de subsunçores individuais, em caráter integrativo dos participantes, remontando aqui a uma versão educacional do conceito de autopoiese. Esse elemento de auto referência retira do processo uma característica puramente analítica, cara ao modelo expositivo simples e linear, e assinala seu caráter mais propriamente sistêmico, conectado a uma estrutura de grafo.

Assim, com as comunidades de investigação e a construção de mapas conceituais integrativos (aqui especificamente com elementos disciplinares da Física e elementos de sua história ou filosofia), várias das etapas propostas por Klein (1990) no âmbito das ações precípuas dos professores, passam para o âmbito das comunidades de investigação, da qual participa de modo privilegiado o professor, certamente, mas que introduz elementos de auto organização próprios, através de sua dinâmica específica. Por exemplo, $2 b, c$, $d$ e $e$, além de $3 a, b$ e, até certo ponto, $c$ passam ao domínio das comunidades de investigação. 


\section{Transposição Didática}

Não podemos supor uma movimentação verdadeiramente interdisciplinar e contextualizada das mencionadas comunidades investigativas, em prol do desenvolvimento cientificamente integrado de conhecimentos, senão pelas vias da transposição didática.

Tomamos por empréstimo a concepção de Chevallard (1991, p. 39) para o termo:

Um conteúdo de saber que tenha sido definido como saber a ensinar, sofre, a partir de então, um conjunto de transformações adaptativas que irão torná-lo apto a ocupar um lugar entre os objetos de ensino. O 'trabalho' que faz de um objeto de saber a ensinar, um objeto de ensino, é chamado de transposição didática.

Entendemos, portanto, que a customização (para um contexto didático) de um saber científico, tipicamente acadêmico, perpassa o ideário, por um lado, do confronto entre a natureza normativa das teorias educacionais e o caráter prescritivo das teorias psicológicas e, por outro, da interdisciplinaridade como vigilância epistemológica.

Sobre o enlace entre as teorias educacionais e psicológicas, a propósito da transposição didática, parece-nos claro que o dito "conjunto de transformações adaptativas" (Chevallard, 1991, p. 39) vige a partir de um binômio operatório que, ao converter saber sábio em saber a ensinar, passa, necessária e sequencialmente, pelos caráteres normativos e prescritivos.

Isto significa, na prática, que a transposição didática é resultado de duas conversões ordenadas do conhecimento:

(a) a primeira deriva de uma reflexão mais abrangente, sobre que tipo de sujeito se deseja formar a partir de determinado saber e, para além disso, a partir de quais parâmetros e calçado em quais visões formativas se busca delinear um saber a ser ensinado (tal como concebe Lipman, por exemplo, ao propor o "pensar crítico" como ortodoxia educacional);

(b) já a segunda, pressupõe um conjunto de processos suficientemente delimitados e direcionados a tipologias específicas de ensino aprendizagem - em termos mais simples, como, a partir de determinada concepção educacional, se formulam, desenvolvem e avaliam práticas muito concretas sobre o ensinar e visando ao aprender (é o caso, por exemplo, da prescrição ausubeliana sobre a aprendizagem significativa).

De outro modo, não se pode conceber o processo de transposição didática, senão por seu viés interdisciplinar, tal como já discutimos neste artigo, como uma dilatada e coordenada interação entre disciplinas com vistas à solução de um problema complexo, insolúvel em âmbito monodisciplinar, do que resulta a integração discursiva entre as áreas do saber, a composição comum de um quadro conceitual que ligue as disciplinas e o estabelecimento de um escopo metodológico partilhado, tudo isso levando a novo conhecimento.

Essa dimensão interdisciplinar da transposição didática, como a queremos conceber, conclama uma permanente vigilância epistemológica:

[...] uma ferramenta que permite recapacitar, tomar distância, interrogar as evidências, pôr em questão as ideias simples, desprender-se da familiaridade enganosa de 
seu objeto de estudo. Em uma palavra, é o que lhe permite exercer sua vigilância epistemológica (CHEVALLARD, 1991, p. 16).

A interrogação das evidências de um objeto de estudo que passa por transposição didática só pode se dar a partir da efetiva contraposição entre uma teoria que normatiza o ensino aprendizagem subjacente e uma outra teoria que descreve e prescreve formas de conversão de saber sábio (científico/acadêmico) em saber a ensinar (modificado para situações de ensino) e este em saber ensinado (recontextualizado). Esse movimento não é linear ou tampouco centrado na relação professor-aluno, sendo influenciado pelo que Chevallard denominou de noosfera, ainda na perspectiva de obstáculos epistemológicos provocados pelo processo (interdisciplinar, como aqui defendido) de transposição didática:

[...] centro operacional do processo de transposição, que traduzirá nos fatos a resposta ao desequilíbrio criado e comprovado [entre os ideais e possibilidades dos saberes científicos] (expresso pelos matemáticos, pelos pais, pelos professores mesmos). Ali [na noosfera] se produz todo conflito entre sistema e entorno e ali encontra seu lugar privilegiado de expressão. Neste sentido [do conflito de interesses], a noosfera desempenha um papel de obstáculo (CHEVALLARD, 1991, p. 34).

A noosfera comporta, portanto, todos os agentes institucionais envolvidos em um processo de transposição didática: sociedade, academia, família, cultura, poder político, professores, família, alunos etc. É nela em que se conflitam perspectivas e visões sobre o objeto em escrutínio, promovendo os obstáculos epistemológicos, isto é, os contrassensos e as discussões sobre a validade do saber em processamento.

Na noosfera, portanto, encontramos o conceito já explicitado de comunidades de investigação, sem as quais não consideramos possível um desenvolvimento efetivamente interdisciplinar do conhecimento. Além disso, sem o que não entendemos possível a concretização do pensar crítico, proposto por Lipman, ou da aprendizagem significativa, proposta por Ausubel.

Com isso, fica demonstrada a conexão íntima entre teoria educacional e teoria psicológica no tocante à construção de um processo educacional (como é o caso do produto de mestrados profissionais em ensino), sob pena de não haver, de fato e na essência, a composição adequada para uma transposição didática (como rigorosamente proposta por Chevallard) ou tampouco o desenvolvimento honesto de práticas inovadoras de ensino que promovam pensamento crítico e levem à aprendizagem significativa.

Neste sentido fica claro que a adoção de uma teoria educacional como a de Lipman introduz extensões, como as relacionadas com a interdisciplinaridade e a transposição didática, sendo que estas também apontariam para mais extensões, no sentido de se construir uma teoria mais completa para a atuação do professor em sala de aula.

Na Figura 3, apresentamos as extensões impostas pela teoria educacional de Lipman, até apenas o ponto em que as apresentamos aqui e, novamente, sem intenção de sermos exaustivos.

\section{Considerações Finais}

As dissertações no âmbito do Mestrado Nacional Profissional em Ensino de Física (MNPEF) têm se mostrado, de modo geral, pouco preocupadas com a dimensão do referencial teórico que adotam. Isto 


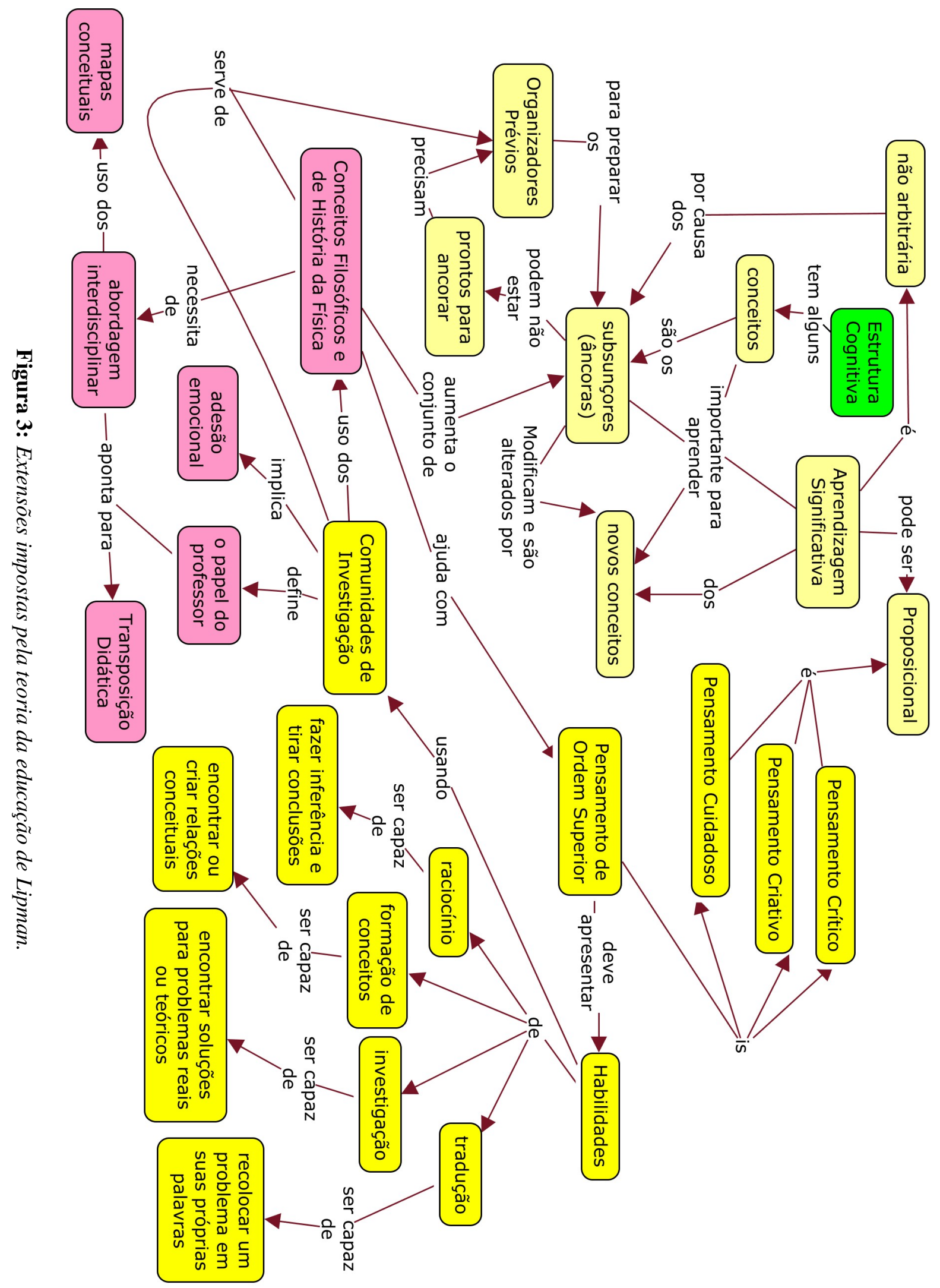


tem tornado tais dissertações desprovidas de nexo interno, de coesão lógico-epistemológica, não raro reduzindo-as à construção de um material pedagógico que poderia ter sido feito sem a necessidade de se ingressar no referido programa de pós-graduação.

Transparece em muitos alunos, afinal professores também, a perspectiva de que já são capazes de construir materiais didáticos com as características adequadas em função da experiência profissional que possuem.

Tal argumento é flagrantemente inconsistente, pois implicaria, a ser verdadeiro, a commpleta futilidade de se cursar o mestrado, que tem por função precípua exatamente ensinar a construir tais materiais educacionais com técnica, consistência e coesão lógica.

Decorre desse estado de coisas, não raro, a adoção frouxa de "uma teoria qualquer", sem a intenção de vê-la espelhada, ainda que implicitamente, no produto construído, e, mais importante, na metodologia de aplicação deste.

Em casos assim, costuma-se adotar abordagens em que apenas uma Teoria de Aprendizagem, de caráter psicológico e descritivo, é apresentada, considerando-se que isso é suficiente para cumprir a obrigação de incluir na dissertação um referencial teórico.

Entretanto, mostramos neste trabalho que não é suficiente a adoção única de tais Teorias de Aprendizagem, mas sim que faz-se sumamente necessária a adoção de uma perspectiva mais próxima do fazer concreto da sala de aula, advindo de Teorias Educacionais, estas sim com uma perspectiva mais axiológica.

Essa dimensão extensiva das Teorias Educacionais em contraste com as Teorias de Aprendizagem fica particularmente clara quando se colocam lado a lado as abordagens de Ausubel e Lipman.

Fica claro que é pelas mãos de uma Teoria Educacional (como, no caso, a de Lipman) que estratégias concretas de ensinar são introduzidas e dão azo à proposição de metodologias. Dentre tais estratégias, podemos mencionar a abordagem interdisciplinar e sua coirmã, a transposição didática, ambas implicitamente propostas na Teoria Educacional de Lipman.

Desse modo, é possível pensar em um contínuo epistemológico que vai das Teorias Psicológicas de Aprendizagem, em uma dimensão de justificação, até as Teorias Educacionais, em uma dimensão axiológica que sugere abordagens ou estratégias com vistas a concretizar o que se afirma no âmbito puramente psicológico. Trata-se de um contínuo justamente por já haver, mesmo nas teorias psicológicas, uma dimensão axiológica menos abrangente, não se tratando, de fato, de uma clivagem entre ambas as dimensões teóricas.

Seja como for, é na passagem de uma Teoria de Aprendizagem, via uma Teoria Educacional, em direção da proposição de uma metodologia que se consideraria apropriada a construção de uma sequência didática.

Sem essa clareza meta-metodológica, acreditamos que arriscam-se os autores das dissertações em mestrados profissionais a realizar um mero exercício de futilidade.

\section{Referências}

[1] BRASIL. Ministério da Educação. Diretrizes Curriculares Nacionais para o Ensino Médio. Brasília: MEC, 1998. 
[2] BRASIL. Ministério da Educação. Diretrizes Curriculares Nacionais Gerais da Educação Básica. Brasília: 2013.

[3] CHEVALLARD, Yves. La Transposicion Didactica: Del saber sabio al saber enseñado. Argentina: La Pensée Sauvage, 1991.

[4] FAZENDA, I. Interdisciplinaridade: qual o sentido? São Paulo: Paulus, 2003.

[5] FERREIRA, M.; LOGUERCIO, R. Q. Análise de Competências em Projetos Pedagógicos de Licenciatura em Física a Distância. Revista Brasileira de Pesquisa em Educação em Ciências, v. 16, n. 2, p. 389-419, 2016.

[6] FOUCAULT, M. A Arqueologia do Saber. Rio de Janeiro: Forense Universitária, 2008.

[7] FOUCAULT, M. História da Sexualidade II. O uso dos prazeres. Rio de Janeiro: Edições Graal, 1984.

[8] FOUCAULT, M. Vigiar e Punir: nascimento da prisão. Petrópolis: Vozes, 1987.

[9] JANTSCH, E. Vers l'interdisciplinarité et la transdisiplinarité dans l'enseignement et l'inovation. In: APOSTEL, L. et. al. (Orgs.). L'interdisciplinarité: problèmes d'enseignement et de recherche dans les universités. Rapport du Séminaraire sur l'Interdisciplinarite, Nice, 1970. Paris: Ceri/OCDE: 1973, p. 98-125.

[10] JAPIASSÚ, H. Interdisciplinaridade e patologia do saber. Rio de Janeiro: Imago, 1976.

[11] JAPIASSÚ, H. O sonho transdisciplinar. Rio de Janeiro: Imago, 2006.

[12] KLEIN, J. T. Crossing boudaries: knowledge, disciplinarities, and interdisciplinarities. Virginia: University Press of Virginia, 1996.

[13] KOCHELMANS, J. J. Interdisciplinarity: history, theory \& pratice. Detroit: Wayne State University Press, 1990.

[14] LATTUCA, L. R. Creating interdisciplinarity: interdisciplinary research and teaching among college and university faculty. Nashville: Vanderbilt University Press, 2001.

[15] LENOIR, Y. Três interpretações da perspectiva interdisciplinar em educação em função de três tradições culturais distintas. Revista E-Curriculum. São Paulo, v. 1, n. 1, dez./jul. 2005-2006.

[16] LIPMAN, M. O pensar na educação. 2. ed. Tradução de Ann Mary Figheiera Perpétuo. Petrópolis: Vozes, 1995.

[17] LIPMAN, M; OSCANYAN, F. S.; SHARP, A. M. A Filosofia na sala de aula. 3. ed. Tradução de Ana Luiza Fernandes Falcone. São Paulo: Nova Alexandria, 2001.

[18] MOREIRA, M.A. (1999). Aprendizagem significativa. Brasília: Editora da UnB. 
[19] MOREIRA, M. A; MASINI, E. F. A. Aprendizagem significativa: a teoria de David Ausubel. São Paulo: Moraes, $2^{\mathrm{a}}$ Edição - 2016 - $4^{\mathrm{a}}$ Reimpressão, 112p.

[20] MOREIRA, M. A. Teorias de aprendizagem. São Paulo: E. P. U., $2^{\text {a }}$ Edição ampliada - 2017a, 243p.

[21] MOREIRA, M. A. Grandes desafios para o ensino da física na educação contemporânea. Rev. Prof. Física, 1, 1 (2017b)

[22] MOREIRA, M. A. Unidades de ensino potencialmente significativas - UEPS. Internet: http://www.if.ufrgs.br/ moreira/UEPSport.pdf (Acesso em: 03/01/2018).

[23] MOZENA, E. R.; OSTERMANN, F. Uma revisão bibliográfica sobre a interdisciplinaridade no ensino das ciências da natureza. Revista Ensaio, v. 16, n. 2, p. 185-206, mai./ago., 2014.

[24] PIAGET, J. L'epistemologie des relations interdisciplinaires. In: APOSTEL, L. et. al. (Orgs.). L'interdisciplinarité: problèmes d'enseignement et de recherche dans les universités. Rapport du Séminaraire sur l'Interdisciplinarite, Nice, 1970. Paris: Ceri/OCDE: 1973, p. 131-144.

[25] POLITO, A. \& COELHO, A. L. M. B., Referenciais teóricos na pesquisa em ensino de Física e o caso da teoria ausubeliana, a ser apresentado no XVII Encontro de Pesquisa em Ensino de Física 2018. Comunicação pessoal com o autor.

[26] REPKO, A. F. Interdisciplinary research: process and theory. Los Angeles/Londres: Sage, 2008.

[27] SOMMERMAN, A. Objeto, método e finalidade da interdisciplinaridade. In: PHILIPPI Jr., A.; FERNADES, V. (Orgs.). Práticas de interdisciplinaridade no ensino e pesquisa. Barueri: Manole, 2015.

[28] WEBER, M. Economia e sociedade: fundamentos de sociologia compreensiva. 3. ed., v. 1. Brasília: UnB, 1994. 